\title{
The Copenhagen Journal of Asian Studies returns to Copenhagen University
}

\author{
KJELD ERIK BRØDSGAARD
}

The Copenhagen Journal of Asian Studies (CJAS) started in 1987 as Copenhagen Papers in East and Southeast Asian Studies. The journal was established as part of the activities of an emerging research environment based at the newly formed interdisciplinary and interdepartmental Centre for East and Southeast Asian Studies at Copenhagen University. The centre was launching a series of seminars and lectures with the participation of prominent foreign scholars and it was felt that publishing revised versions of their talks in a Copenhagen publication would put the local research environment on the global map.

The activities of the Centre for East and Southeast Asian Studies (CØS) were part of an effort to promote studies of modern Asia. For many years, classical studies of Asia, and in particular China, dominated the field in Copenhagen and in fact in most of the Nordic area. However, a new generation of young scholars was emerging with an interest in Modern Asian Studies but lacking an institutional framework for their work. The establishment CØS, including its publication series Copenhagen Papers in East and Southeast Asian Studies and Copenhagen Discussion Papers, provided such a framework.

In my capacity as director of CØS, in February 1988 I went to the airport to pick up the renowned political scientist Robert Scalapino, who had accepted an invitation to initiate one of CØS' new lecture series. When I introduced him to our plans of publishing his and other visiting scholars' revised lectures in a new journal, he looked at me and asked whether I had any idea of the amount of work we would have to put into running a journal: he said this from his experience as chief editor of Asian Survey and head of the impressive book publication series at Berkeley's East Asian Institute, which he was directing at the time.

Professor Scalapino was right. A huge amount of work was involved in starting the journal. We had to do everything ourselves - reviewing submissions, copyediting, typesetting the papers and doing the proofreading. Fortunately a visiting scholar and former chief economist at the World Bank by the name of Thiagarajan Manoharan took an interest in our work and was of invaluable assistance in improving the quality of 
the journal, in evaluating submissions and helping me get the publication off the ground.

The first issues were mainly special issues based on revised papers originally presented at the Centre's international lecture series. After publication of the first three issues, Copenhagen Papers was turned into a regular publication published twice a year. A few years later, in 1994, it was decided to change the journal's name from Copenhagen Papers in East and Southeast Asian Studies to The Copenhagen Journal of Asian Studies (CJAS).

When the Centre for East and Southeast Asian studies was closed down in 2001, responsibility for publishing the journal was transferred to the department of Asian Studies at Copenhagen University. When I moved to Copenhagen Business School (CBS) in 2003 to take up a professorship and the directorship of Asia Research Centre, an agreement was signed that made it possible for me to bring CJAS with me. The agreement also stipulated that in the event CBS should cease publishing the journal, Copenhagen University would have the option of taking it back.

Recently at CBS a number of Centres have been closed, including the Asia Research Centre. As a consequence, there is no longer funding available for running CJAS. Fortunately, the University of Copenhagen has agreed to take back the journal. It will be located at Department of CrossCultural and Regional Studies (ToRS), which was established in 2004 as the result of a merger of a number of departments in Asian and Central Asian Studies, including the former department of Asian Studies. In a way this arrangement signifies the coming home of the journal. I wish to thank the head of ToRS, Ingolf Thuesen, for making this possible.

The new hosts of the journal will have complete freedom to develop their own mission and vision statements, editorial policies and to form a new editorial board. It is our understanding that this will be done with due reference to the journal's background and history.

Over the years we have published 32 volumes and 63 issues of CJAS. Papers range from business studies to studies of religion, culture and ideology. In the beginning CJAS published solicited papers based on seminar and lecture series held in Copenhagen initiated by the Centre. Later the journal increasingly published papers by Scandinavian scholars. The reason for this was to provide a window to the outside world for Scandinavian scholarship in Asian studies.

One can also detect a shift in topics covered in the journal. At the outset the journal contained papers addressing big issues such as China-Soviet relations, China-US relations, East and Southeast Asia 
in the world economy. A wide range of leading figures in the field contributed, including Robert Scalapino, Chalmers Johnson, Tu WeiMing, Harry Harding, Gerald Segal, Stuart Schram and James C. Scott. Later there was a shift to more detailed studies focusing on narrower topics. Such a change reflected developments within the field of Asian Studies. Some would call it a maturing of the field; others would deplore the lack of overview and comprehensiveness. When the journal was launched, studies of modern Asia were only slowly evolving in Scandinavia. Today modern and contemporary studies dominate the field and classical studies have receded. Perhaps it is time to partially reverse or at least arrest this process, recognizing that understanding and explaining modern and contemporary developments in Asia requires knowledge of the past.

Since the journal was established, the world of publishing has been revolutionized. In the 1980s and 1990s, journals were published and read in hard copy. Today most journals are read online, and journals are increasingly included in packages offered by major publishing outlets, who profit a great deal by this arrangement. CJAS is also available online through the library of CBS. It is no secret that this shift in favour of online publishing has had adverse effects on the number of regular subscribers. Why pay for hard copies when you can download articles for free from CBS home page? Personally I belong to the old school and believe there is a great value in publishing and owing publications in hard copy, but I am probably fighting a losing battle. In any case, it is up to the new owner and publisher to make decisions on these matters.

I would like to take the opportunity to thank CBS for housing CJAS since 2003. I would also like to thank Viggo Brun and Can Seng Oi for serving as editors in 1996-2001 and 2007-2010 respectively.

KJELD ERIK BRØDSGAARD founding Editor of CJAS 